\title{
Uncovering the hidden impacts of inequality on mental health: a global study
}

\author{
Shoukai Yu (10)
}

\begin{abstract}
Women are nearly twice as likely as men to suffer from mental illness. This gender disparity in depressive disorders may relate to social inequalities and living standards across nations. Currently, these disparities were not reflected at the level of health policies. This study utilized global data for depressive disorders and socioeconomic data from the United Nations' World Bank databases and Global Burden of Disease database to demonstrate the correlation between social inequality and gender disparities in mental health. This study investigated the association among the ratio of female to male depressive disorder rates, gross domestic product, the GINI Index, and the gender inequality index for 122 countries. The research yielded some major findings. First, there exists a significant correlation between gender inequality and gender disparities in mental health. Second, the GINI index is significantly associated with male-but not female-depressive disorder rates. Third, gender disparities in depressive disorders are associated with a country's wealth. These findings can help to inform society, policy-makers, and clinicians to improve the overall health level globally.
\end{abstract}

\section{Introduction}

According to the World Health Organization (WHO), depressive disorders are major contributors to the world's health burden; they affect approximately 350 million people worldwide ${ }^{1-3}$. Women are nearly twice as likely as men to suffer from mental illness ${ }^{4-6}$. Although this gender disparity in mental health is reported across diverse geographical regions, societies, populations, and social contexts, there is a dearth of research that explores a link between the impacts of social inequalities and gender disparities on mental health. In this study, the social inequalities include both gender inequality and wealth inequality. Understanding gender disparities in health is very important, according to the National Institutes of Health $^{7-10}$. A growing body of research indicates that psychiatric disorders are largely caused by a combination of stress, environmental, neurobiological, and genetic factors. These poorly understood factors significantly limit the development of effective treatments for these

\footnotetext{
Correspondence: Shoukai Yu (shoukaiyu@hsph.harvard.edu)

${ }^{1}$ Harvard T. H. Chan School of Public Health, Harvard University, Boston, MA, USA
}

disorders. The major causes for depressive disorders cannot be completely explained by genetic factors ${ }^{11-13}$. The contributions of genetic architectures are difficult to address at the level of health policy. Therefore, attention to social factors, especially with regard to inequality, is critical in approaches to mental health; these factors can be improved dramatically through the implementation of appropriate governmental policies and heightened community awareness.

The brain structure and response to stress are different between females and males ${ }^{14,15}$. For example, community pressure regarding stereotypical social roles based on gender may impact mental health responses differently in women and $\operatorname{men}^{16}$. In a male dominated culture, women and men may deal with competition in their workplaces differently. Previous studies also investigate the potential relationship between hegemonic masculinity and mental health in men ${ }^{17-19}$. Human genetic variation exists both within and among populations. These relevant genetic characteristics as well as stress could contribute to gender disparities in mental health ${ }^{20}$. The gender expectations and masculinities may also play an important role in 
gender disparities in mental health ${ }^{17,21,22}$. In a more general context, gender inequality includes but not limited to domestic violence, sexual abuse, unpaid caring work, higher hours of work, low social status, lack of access to reproductive rights and education ${ }^{23-27}$. Furthermore, the areas related to gender inequality include public health, social work, sociology, and social psychology.

Both gender inequality and wealth inequality have an impact on women's health at the country level ${ }^{26,28,29}$. For gender inequality research, a series of WHO reports provided in-depth reviews of available literature on the topic of gender equality and mental health in $2000^{30}$. Since then, there are some studies that have attempted to examine the association between gender inequality and gender disparity in mental health at the country level ${ }^{31,32}$. However, until now the evidence remains inconsistent for the possible impact of gender inequality on gender disparity in mental health ${ }^{31-34}$. In 2007 , one study utilized the data from both high income and low and middle income countries and proved that gender equality has no or little impact on the gender disparities in depressive disorders $^{32}$. In 2013, one study, based only on European countries, claimed the potential impact of gender equality on reducing the gender disparity in depressive disorders. Unfortunately, they were unable to provide statistical evidence to prove this association ${ }^{31}$. Therefore, at the global level, the direct statistical evidence to show the association between gender equality and the gender disparity in depressive disorders remains absent.

Wealth inequality has become a frequently and widely discussed topic ${ }^{31,35-38}$. Wealth inequality has impacted general health, including mental health ${ }^{39-42}$. Furthermore, the impact of wealth inequality on mental health has also been investigated ${ }^{43-45}$. Wealth inequality and income inequality are different (Note 1): income represents the money received on a regular basis, while wealth represents the money or properties owed over a lifetime. However, research that attends to gender disparity in depressive disorders and the wealth inequality is limited.

This paper presented the statistical evidence to address this gap in the literature. The WHO has published a series of comprehensive reports about mental health ${ }^{34,46,47}$ and has made a significant effort to collect the data that has permitted an exploration of the gender disparities in mental health ${ }^{29,30}$. The study in this paper captured the impact of social inequality on gender disparities in mental health. Previous studies that have not adequately addressed this problem typically analyzed the data using gender (Notes 2) as a dichotomous variable. Moreover, the scope of many studies has been limited to specific countries $^{24,48-51}$. For example, one study that indicated the potential correlation between the wage gap and gender disparities in mood disorders was limited to the
United States and only used the wage gap to measure gender inequality ${ }^{24}$. Another study conducted only in South Korea also indicated that gender inequality might have an impact on mental health. In 2004, one study ${ }^{27}$, conducted in the United Kingdom, indicated domestic violence and abuse toward women related to the greater prevalence of mental illness among women. There is a need to utilize global datasets to identify the impact of inequality on mental health. Unlike existing studies, this study utilized mental health datasets at a global level to conduct the analysis; and the analyses in this study directly focused on the gender disparities on mental health. The novelty of the study in the paper lied in both data integration and the analysis. In order to illustrate the way that the present analysis can be used to better capture the relationships between mental health and inequality, this research also focused specifically on depressive disorders. All of the data were extracted from publicly available datasets and these data represent the largest sample size so far, due to the recent availability of global data on depressive disorders from the Global Burden of Disease database. The novelty analysis was straightforward: the ratio of depressive disorder rates for female to male is used directly as a dependent variable. In this way, gender disparity in depressive disorders can be modeled directly.

A series of statistical models were applied to examine the relationship between gender disparities in mental health and socioeconomic factors. Particular attention was paid to both gender and wealth inequalities. The study aimed to identify whether or not gender disparities in mental health are related to social inequalities, as well as to identify whether or not females respond differently to stress provoked by social inequality as evidenced in mental health outcomes. In this study, social inequality included both wealth inequality and gender inequality. The research was designed to inform public policy as well as to help health professionals reduce gender disparities in mental health and broadly improve mental health outcomes.

\section{Methods}

\section{Data sources}

Mental health data were obtained from the Global Burden of Disease datasets (GBD) website (http://www. healthdata.org/gbd/data, 1 May 2016) ${ }^{2}$. The socioeconomic factors analyzed in this study were the Gender Inequality Index (GII), the GINI Index, and Gross Domestic Product (GDP).The socioeconomic data (GII, GINI Index, and GDP) were obtained from the United Nations' databases (World Bank and World Economic Forum, 1 May 2016) ${ }^{52-54}$. All datasets were combined by country codes. 


\section{The dependent variable}

For mental health data, depressive disorders data, including major depressive disorders and dysthymia, were extracted from the GBD database. In order to obtain the most comprehensive dataset, this study include all clinical case definitions that are consistent with the description of diagnostic criteria for the International Classification of Diseases (ICD $)^{55}$ or Diagnostic and Statistical Manual of Mental Disorders (DSM) ${ }^{56}$. The difference between the diagnostic criteria has been tested and no significant difference has been identified ${ }^{57}$.

In the GBD, the Disability-Adjusted Life Years (DALYs) were calculated by arriving at a sum of the total years of life lost due to premature mortality and the years of life lived with disability to measure health loss based on both mortality and non-fatal health burdens ${ }^{2,15,46}$. The DALY burdens of depressive disorders were obtained from the GBD by country, region, age, and gender for the years 1990, 1995, 2000, 2005, 2010, and 2015. The gender data included the rates of depressive disorders for females, males and both combined. The rates of depressive disorders are referring to the rate per 100,000 of depressive disorders measured by the DALYs. The DALYs combines premature mortality as years of life lost (YLLs) and disability as years lived with disability (YLD) ${ }^{58,59}$. According to $\mathrm{WHO}^{2}$, estimates of mood disorders, anxiety disorders, and schizophrenia were calculated and improved with epidemiological evidence and, modified health states and disability weights for GBD databases in $2000 \mathrm{~s}^{60,61}$.

The first dependent variable in this study is the logtransformed ratio of depressive disorder Rates for Female to Male (log-transformed RRFM) per 100,000. The second dependent variable in this study is DALYs for Depressive Disorder Rates Per 100,000 persons (DDRP) for either of gender.

\section{The independent variables}

The study utilized GII data to determine gender inequality ${ }^{53}$. The GII is a composite measurement of gender inequalities. It measures the loss for women as a result of gender inequality in three areas: reproductive health, empowerment, and the labor market. This index ranges from 0 to 1 ; the higher value indicates a greater level of inequality. The United Nations Development Programme introduced the GII index in its 2009 and data are available from World Economic Forum Global Gender Gap Index 2014 $4^{53,54}$.

For socioeconomic data, the GINI Index measures wealth inequality as a distribution of a country's residents. The index ranges from 0 to 1 , and the higher value indicates greater inequality. The GDP measures monetary value of all final goods and services produced in a specific time period. Per capita GDP, in purchasing power parity units may be obtained from World Data Bank. Both GDP and the GINI Index are World development indicators. For the purposes of this study, both the GINI and GDP were obtained in current international currency from the World Bank for the years 1990, 1995, 2000, 2005, 2010, and 2015. The average for those years was calculated for each country. The selection of countries was based on the availability of mental health and socioeconomic data, including GII, the GINI Index, and GDP. The countries with missing data in any of the following categories were removed: depressive disorders, GBD, GII, GINI Index, and GDP.

\section{Measures}

A log-transformed RRFM per 100,000 of depressive disorders was estimated as dependent variable. The independent variables include socioeconomic factors determined by using GII, GINI, and GDP with random intercepts determined for ages and regions. The data preparation included log-transformed RRFM and rescaled socioeconomic indexes by a traditional z-score transformation. The log-transformed RRFM allowed the data to more closely reflect a normal distribution. Similarly, the rescaling of socioeconomic indexes permitted the data to be handled more appropriately for statistical analysis than directly using socioeconomic factors as their original scale, because the original scale of GII and GINI ranges from 0 to 1 ; while the original scale of GDP ranges from 0 to a real number.

\section{Control variables}

The control variables include ages, regions, and years. Age groups were divided into the following categories: under 5 years of age, 5-14 years of age, 15-49 years of age, 50-69 years of age, and 70 years of age or older. Mental health data from 122 countries (Fig. 1) for seven super-regions were included. The super-regions were East Asia \& the Pacific, Europe \& Central Asia, Latin America \& the Caribbean, the Middle East \& North Africa, North America, South Asia, and Sub-Saharan Africa (Table 1). The years were 1990, 1995, 2000, 2005, 2010, and 2015.

\section{Statistical analysis}

The mixed models ${ }^{62}$ were fitted using STATA $14^{63}$. There were six models that were appropriate for the investigation of the relationship between GII and logtransformed RRFM. In the first model, the logtransformed RRFM was estimated as dependent variable. The independent variables include GII, GINI, GDP, and region, with age as a random effect. In the second model, the log-transformed RRFM was estimated as dependent variable. The independent variables include GII, GINI, and GDP, with age, year, and region as random effects. 

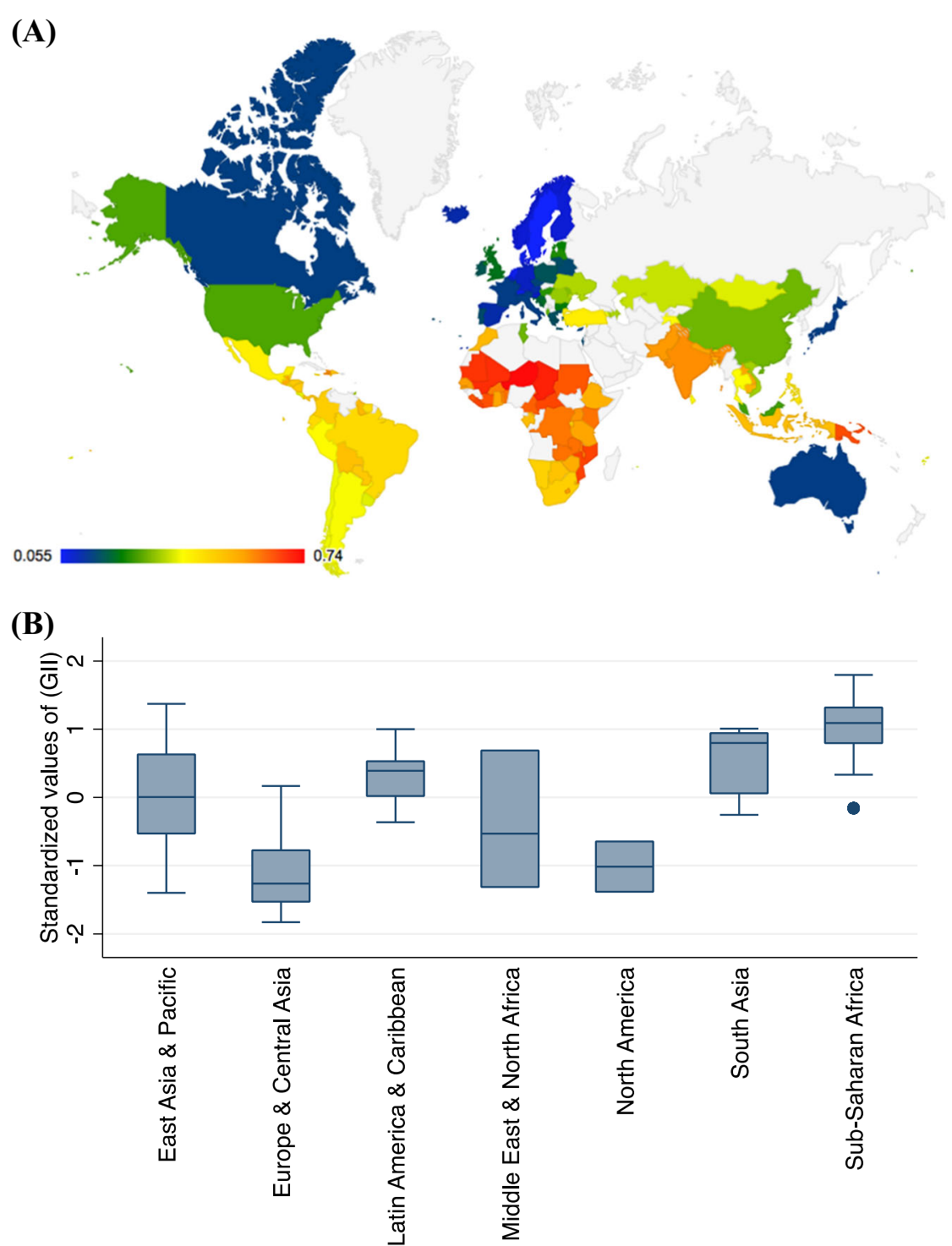

Fig. 1 The gender inequality index of countries and seven regions. a The map of analyzed countries with their gender inequality index, red color means higher inequality. b Gender inequality index for the seven regions, higher values mean higher inequality

For model 2, the formula is:

$$
\begin{gathered}
\log \left(\text { relative_rate } e_{i j k}\right)=\beta_{0}+\beta_{1} \times G I I+\beta_{2} \times G I N I \\
+\beta_{3} \times G D P+b_{i}+c_{j}+d_{k},
\end{gathered}
$$

where the component relative_rate $i j k$ is the relative ratio of female to male mental disorder (Ratio of Rates for Female to Male) as a function of GII, GINI, GDP for region $k$, year $j$, and age $i$. The random effects are age $b_{i}$, year $c_{j}$, and region $d_{k}$. The equation highlights the relationship between relative ratio and gender inequity.

In the third model, the log-transformed RRFM was estimated as dependent variable. The independent variables include GII, GINI, GDP, region, and age, with no random effect variables. The purpose of fitting the third model was to compare the difference of coefficients between the mixed models and a linear regression model. These models highlighted the relationship between the log-transformed RRFM and gender inequality and wealth inequality, with adjustments for GDP. The potential collinearity among predictors was examined using variance inflation factors (VIF). The direct relationship between log-transformed RRFM and GII also was calculated using a Pearson correlation.

Models 4, 5, and 6 were fitted to best identify whether or not the rate per 100,000 of depressive disorders (DDRP) evidenced a direct relationship with any of the socioeconomic factors for females or males. The female DDRP 
Table 1 Number of countries included from each superregion

\begin{tabular}{ll}
\hline Region & Number of countries \\
\hline East Asia \& the Pacific & 15 \\
Europe \& Central Asia & 39 \\
Latin America \& the Caribbean & 23 \\
The Middle East \& North Africa & 3 \\
North America & 2 \\
South Asia & 7 \\
Sub-Saharan Africa & 33 \\
Sum & 122 \\
\hline
\end{tabular}

(Model 4), male DDRP (Model 5), and both genders' DDRP (Model 6) were separately estimated as dependent variable. The independent variables include GII, GINI, GDP, with age and region as the random effects.

\section{Results}

The depressive disorder rates per 100,000 population (DDRPs) remained relatively stable from 1990 to 2015 for females and males (Fig. 2). For all seven of the superregions, the mean number of depressive disorders for females was approximately twice that of males, with a range from 1.63 to 3.89. Based on the data from the GBD (Fig. 2), the Sub-Sahara African region had the highest number of depressive disorders for both females $(453,705)$ and males $(225,474)$, whereas the East Asia \& Pacific region had the lowest number of depressive disorders for both females $(190,818)$ and males $(60,777)$. The SubSahara African region yielded the highest value, while the regions of Europe \& Central Asia the lowest value for gender inequality.

Statistically significant correlations were found between the log-transformed RRFM and GII, as well as between

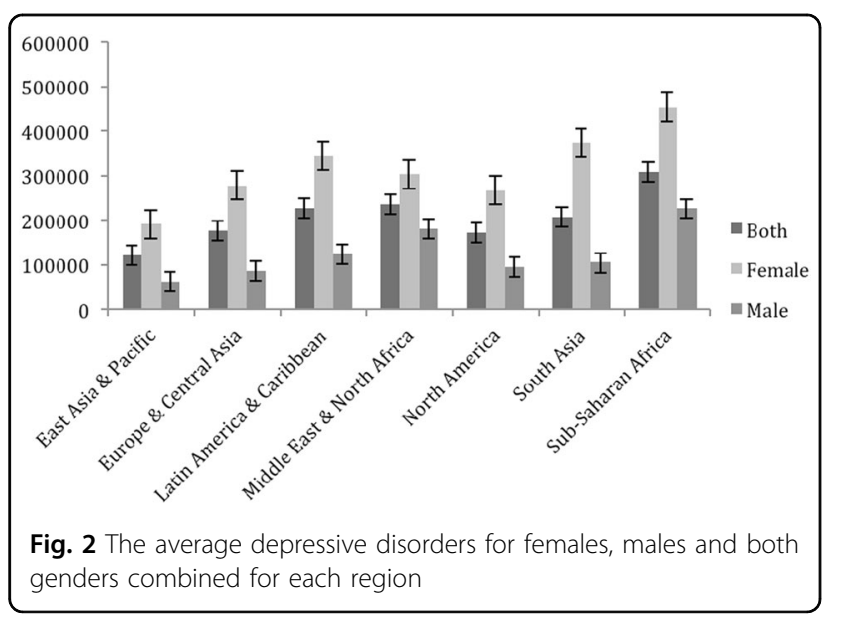

the log-transformed RRFM and GINI index once the mixed effect model was fitted (Table 2). The estimates from the three models were very similar. In Model 1, the VIF score for GII is greater than 2; for Model 2, in which the region effect was considered as a random effect, all of the VIF scores were less than 1.8.

There was a significant association (Table 2) between the GII and RRFM. However, no direct associations were found between the GII index and female DDRP and no associations were found between the GII index and the male DDRP (Table 3, Models 4 and 5). Furthermore, there were no associations found between the GII and DDRP for both genders (Model 6 in Table 3). The results together demonstrate that GII index is a hidden factor that correlated with the log-transformed ratio of female to male rates of depressive disorders.

Interestingly, there were associations between GDP and RRFM (Table 2). Moreover, DDRP for both genders evidenced significant associations with GDP (Table 3; Model 6: $-0.048[-0.074,-0.021], P$-value $<0.001$ for both genders). This shows that societies with higher GDP had lower rates of depressive disorders for both genders.

Greater GII was related to greater RRFM (Relative Ratio (RR) in Table 2 Model 1: 1.043, [1.034, 1.053]; $P$-value < 0.001). However, for the GINI Index, the greater GINI Index at the country level was related to lower RRFM (RR in Table 2 Model 1: 0.976, [0.971, 0.982]; $P$-value < 0.001). For the GDP, there was a significant association between RRFM and GDP. Additionally, the Pearson's correlation coefficient for RRFM and the GII index were significant $(-0.151 ; P$-value $<0.001)$.

\section{Discussion}

This study demonstrated that social inequalities demonstrated a differential impact on mental health for females and males. For GII, greater gender inequality was significant (Model 1: 1.043, [1.034, 1.053]; $P$-value $<0.001$ ) and related to the decreased gender disparity in depressive disorders. This finding strongly suggested that women suffer mentally more than men in societies with greater levels of gender inequality. Combined with the significant correlation between RRFM and the GII index (1.043 $[1.034,1.053], P$-value $<0.001)$, gender inequality had a significant impact on gender disparities in depressive disorders. This study provided evidence that social factors, especially gender inequalities may have significant impact on gender disparities in depressive disorders.

This study identified three major findings. First, gender inequality was significantly associated with increased gender disparities in depressive disorders. Previous studies that analyzed depressive disorders separately for females and males failed to detect the association between GII and mental disorder rates that was found here (Table $3)^{11}$. This study demonstrated that gender inequality may 
Table 2 Results of statistical analysis between Ratio of Rates for Female to Male (RRFM) and socioeconomic status (GII, GINI, and GDP) for Models 1-3

\begin{tabular}{|c|c|c|c|c|c|c|}
\hline & \multicolumn{2}{|l|}{ Model 1} & \multicolumn{2}{|l|}{ Model 2} & \multicolumn{2}{|l|}{ Model 3} \\
\hline & Exp beta $(95 \% \mathrm{Cl})$ & $P$ value & Exp beta $(95 \% \mathrm{Cl})$ & $P$ value & Exp beta $(95 \% \mathrm{Cl})$ & $P$ value \\
\hline Intercept $\left(\beta_{0}\right)$ & $1.252(1.157,1.357)$ & $<0.001$ & $1.275(1.179,1.378)$ & $<0.001$ & $1.072(1.059,1.085)$ & $<0.001$ \\
\hline $\mathrm{G} \|\left(\beta_{1}\right)$ & $1.043(1.034,1.053)$ & $<0.001$ & $1.039(1.032,1.045)$ & $<0.001$ & $1.043(1.034,1.053)$ & $<0.001$ \\
\hline $\mathrm{GINI}\left(\beta_{2}\right)$ & $0.976(0.970,0.982)$ & $<0.001$ & $0.976(0.971,0.982)$ & $<0.001$ & $0.976(0.970,0.982)$ & $<0.001$ \\
\hline $\operatorname{GDP}\left(\beta_{3}\right)$ & $1.038(1.031,1.045)$ & $<0.001$ & $1.042(1.033,1.051)$ & $<0.001$ & $1.043(1.034,1.053)$ & $<0.001$ \\
\hline
\end{tabular}

Model 1, RRFM was estimated as dependent variable. The independent variables include GII, GINI, GDP, and region, with age and year as random effects Model 2, RRFM was estimated as dependent variable. The independent variables include GIl, GINI, and GDP, with age, region, and year as random effects Model 3, RRFM was estimated as dependent variable. The independent variables include GIl, GINI, GDP, region, and age, with no random effect variables

be associated with slightly higher DDRP for females (Model 4: 0.039 [0.001, 0.081], $P$-value $=0.061$ ). Moreover, gender inequality was associated with slightly lower DDRP for males (Model 5: -0.027 [-0.067, 0.013], Pvalue $=0.180)$. This study identified a significant association (Model 1: 1.043 [1.034, 1.053], $P$-value < 0.001) at the level of ratios, rather than at the level of rates. This distinction permitted an identification of the role that gender inequality played in depressive disorders.

Table 3 provides the information about the relationship between gender inequality and the mental health for female and male separately. For female, the estimate 0.039 $[0.001,0.081]$ is larger than 0 , which indicates the greater gender inequality is related to the greater depression rate for women. While for male, the estimate -0.027 [ -0.067 , 0.013 ] is less than 0 , which indicates the greater gender inequality is related to the lower depression rate for men. Both estimates do not reach the significance level for $\mathrm{p}$ values, while the $P$ value for the ratio of female rates to male rates is significant (Table 2). This is also one of the reasons why this association between gender inequality and mental health is hidden. Gender inequality includes but not limited to domestic violence, sexual abuse, unpaid caring work, higher hours of work, low social status, lack of access to reproductive rights and education ${ }^{23-27}$. The stress responses have been linked to depression ${ }^{43,64}$. In a male dominated culture, women and men may deal with competition in their workplaces differently. Previous studies also investigate the potential relationship between hegemonic masculinity and depressive disorders in $\operatorname{men}^{17-19}$.

Second, men suffered from more mental health problems than women when dealing with situations of high wealth inequality (Models 4 and 5). This finding challenged assumptions that females would prove more emotionally or mentally sensitive to many social inequalities $^{65,66}$. However, a high GINI index was significantly associated with high DDRP for males (Model 5: 0.027 [0.001, 0.053], $P$-value < 0.05), whereas a high GINI index is not associated with high DDRP for females (Model 4: $-0.013[-0.039,0.014], P$-value $=0.353)$. This result is noteworthy and expands upon the contributions made by a recent study ${ }^{24}$ that indicated that the wage gap may be related to higher rates of major depression for females in the United States. One possible explanation could be that males are more mentally sensitive to wealth inequality, due to either stress or their genetic makeup $^{20,33,67,68}$. From a biological point of view, the

Table 3 Results of statistical analysis between Depressive Disorder Rate Per 100,000 population (DDRP) and socioeconomic status (GII, GINI, and GDP) for Models 4-6

\begin{tabular}{|c|c|c|c|c|c|c|}
\hline & \multicolumn{2}{|l|}{ Model 4} & \multicolumn{2}{|l|}{ Model 5} & \multicolumn{2}{|l|}{ Model 6} \\
\hline & Beta $(95 \% \mathrm{Cl})$ & $P$ value & Beta $(95 \% \mathrm{Cl})$ & $P$ value & Beta $(95 \% \mathrm{Cl})$ & $P$ value \\
\hline Intercept $\left(\beta_{0}\right)$ & $0.119(-0.888,1.123)$ & 0.817 & $-0.217(-0.990,0.556)$ & 0.582 & $-0.042(-0.936,0.852)$ & 0.926 \\
\hline GII $\left(\beta_{1}\right)$ & $0.039(0.001,0.081)$ & 0.061 & $-0.027(-0.067,0.013)$ & 0.180 & $0.002(-0.034,0.038)$ & 0.904 \\
\hline $\operatorname{GINI}\left(\beta_{2}\right)$ & $-0.013(-0.039,0.014)$ & 0.353 & $0.027(0.001,0.053)$ & 0.040 & $0.008(-0.016,0.031)$ & 0.531 \\
\hline $\operatorname{GDP}\left(\beta_{3}\right)$ & $-0.019(-0.048,0.011)$ & 0.209 & $-0.068(-0.098,-0.039)$ & 0.001 & $-0.048(-0.074,-0.021)$ & 0.001 \\
\hline
\end{tabular}

Model 4, female DDRP was estimated as dependent variable. The independent variables include Gll, GINI, GDP, with age and region as random effects Model 5, male DDRP was estimated as dependent variable. The independent variables include GII, GINI, GDP, with age and region as random effects Model 6, both genders' DDRP was estimated as dependent variable. The independent variables include GII, GINI, GDP, with age and region as random effects 
presence of the $\mathrm{Y}$ chromosome and different hormones could also contribute to brain reactions to the wealth inequality. Yet, stereotypical social roles could put pressure on men to excel in the work place, producing greater levels of stress in men. This possibility would reaffirm the need to address inequality as an integral part of a plan to improve mental health among males. The higher GINI index was significantly associated with lower RRFM (Table 2, Models 1-3). However, the decreased gender disparity in depressive disorders was due to an increased DDRP for males, as opposed to a lower rate of depressive disorder rate among females.

Third, the GDP showed a direct association with RRFM, after adjusting for other socioeconomic factors and regional effects. Yet, the higher GDP correlate with slightly higher RRFM. Moreover, GDP did correlate with the prevalence of depressive disorders for both genders (Model 6). This finding would suggest that higher overall wealth level for a country is not related to reducing gender disparity in depressive disorders. However, improving the overall level of wealth may indeed reduce the prevalence of depression in a specific population ${ }^{69-71}$.

In addition to this work's three major findings, there was one other finding that merits mention. Different geographical locations showed different regional impacts on gender disparities associated with depressive disorders (Fig. 1). This finding was consistent with those from previous studies ${ }^{57,72,73}$. These results indicate that regional or geographical effects, as well as genetic factors (population differentiation, human genetic variation for different human populations), potentially played a role in gender disparities in depressive disorders. Regional and geographical variations could be due to the combination of effects of cultural, environmental, and socioeconomic factors.

There is substantial variability existed in GII index between countries (Fig. 1). Similarly, there are also substantial variability existed in GINI index (Supplementary Figure 1) and GDP (Supplementary Figure 2) between countries. The high wealth inequality countries tend to cluster at Latin America and Caribbean, and some countries in the south part of Sub-Saharan Africa. The countries with higher GDP tend to have lower GINI index, such as Canada, the USA, Australia, and countries in Europe. Furthermore, there are some developing countries, such as China and some countries in the north part of Sub-Saharan Africa, although the GDP is not very high, the wealth inequality index is relatively low, which demonstrate the indirect correlation between GDP and GINI index. Overall, there is a cluster tendency for all of the three independent variables. Compared to the other two independent variables, the cluster tendency for GDP index is stronger.

\section{Conclusion}

This is one of the first studies to successfully provide statistical evidence of an association between gender disparities in psychiatric disorders and social inequalities at a global level. These results contribute to the growing evidence that social inequality has an independent effect on population-specific depressive disorders ${ }^{24,48}$. This study was enhanced by a multi-faceted approach to the matter of inequality that utilized both the United Nations' definition of inequality and measures of inequality such that gender inequality could be captured more precisely. The novelty in the paper lied in the analysis using existing databases. The overall results suggested that diverse aspects of social inequality, including both gender inequality and wealth inequality, evidenced differential impacts on mental health for both genders.

Caution should be exercised in interpreting and extrapolating the study results to posit broader generalizations regarding mental health. The study results only demonstrated correlations rather than causal links between inequality and depressive disorders. A focus on causal relationships between policies, such as economic, education and public health and mental health may not adequately capture the complexity of social interactions and the nature of mental disorders. The causal relationship could be further explored from the genomics and etiology aspects. Moreover, this study analyzed gender inequality and wealth inequality at the country level, and there is no apparent correlation between GII and GINI indexes. If future analysis is utilized for research on a local scale, such as at the level of community or county, the correlation between gender inequality and wealth inequality should be taken into account in the modeling process. Furthermore, attention should be drawn to the potential collinearity between the independent variables. Additionally, this study was based solely on the genders recorded in the GBD database (female, male, and both combined), with no information on lesbian, gay, bisexual, and transgender populations.

Improvement in a given population's mental health would require a multidisciplinary policy approach that addresses socioeconomic determinants of health. Wealth inequality has become a pressing issue in a wide range of countries internationally ${ }^{23,74-76}$. Moreover, many researchers have shown that socioeconomic status has impacted general health ${ }^{39-42}$. Recently, many studies have focused on the gender differences regarding health ${ }^{77-80}$. Unlike most previous studies on inequality and health, this research specifically demonstrated the association between the effects of socioeconomic inequality gender disparities on mental health. Future research could further explore the causal relationships that might exist between social factors and mental health outcomes. Currently, the global burden of disease database lack 
country level data for mental health for majority countries $^{81}$. The data at the country level for the global burden of disease study could further improve our understanding the association between socioeconomic determinants and mental health.

The findings presented here provided strong evidence of a relationship between high gender inequality and a higher ratio of depressive disorder rates for both females and males. This significant correlation might be partially explained by gender discrimination. Gender prejudice, either overt or covert, could subject females to the experience of greater barriers to accessing community resources, including mental health care, that contribute to better health. The regions that exhibited high rates of common mental disorders also exhibited high levels of inequality, as reported by the $\mathrm{WHO}^{6}$. The United Nations emphasized the need for increased attention to factors that link gender disparities to health, including education, inclusion in policy decisions, participation, income, and differential socioeconomic status in its 17 sustainable development goals. It would be important to focus on the impact of policies designed to further equality, including both gender equality and wealth equality, in order to address existing mental health disparities and achieve the highest possible level of health for all people.

\section{Notes}

1. The definitions of income inequality and wealth inequality are different. However, wealth and income inequality usually are not distinguished by their original definitions in the existing literature on the GINI index. Therefore, in this paper, wealth inequality is used to denote all wealth and income equalities, unless the inequality is only measured by income. Then the phrase income inequality will be used.

2. According to the $\mathrm{WHO}$, gender refers to the range of socially constructed roles and characteristics of women and men; sex refers to biological differences ${ }^{82,83}$. The aim of this study is to emphasize the impact of both gender inequity and socioeconomic inequality on mental health at the country level. Moreover, the causes of depressive disorders are related to combined social and biological effects. Therefore, in this paper, the word gender is used to denote all sex and gender differences, unless those differences can be fully attributed to biological differences. Then the word sex will be used.

3. For socioeconomic data, the GDP measures monetary value of all final goods and services produced in a specific time period. Per capita GDP, in purchasing power parity units may be obtained from World Data Bank. The GINI Index measures wealth inequality as a distribution of a country's residents. The index ranges from 0 to 1 , and the higher value indicates greater inequality. Both GDP and the GINI Index are World development indicators.

4. The GII is a composite measurement of gender inequalities. It measures the loss for women as a result of gender inequality in three areas: reproductive health, empowerment, and the labor market. This index ranges from 0 to 1 ; the higher value indicates a greater level of inequality. The United Nations Development Programme introduced the GII index in its 2009 and data are available from World Economic Forum Global Gender Gap Index 2014 for 141 countries $^{53,54}$.

\section{Acknowledgements}

I thank members of the Department of Environmental Health and the Department of Biostatistics at Harvard University for discussions and insightful comments during development of this work. I also thank my advisor Dr Bernardo Lemos at Harvard University for his support.

Conflict of interest

The author declares that she has no conflict of interest.

\section{Publisher's note}

Springer Nature remains neutral with regard to jurisdictional claims in published maps and institutional affiliations.

Supplementary Information accompanies this paper at https://doi.org/ 10.1038/s41398-018-0148-0.

Received: 25 September 2017 Revised: 28 January 2018 Accepted: 3 April 2018

Published online: 18 May 2018

\section{References}

1. Marcus, M., Yasamy, M. T., van Ommeren, M., Chisholm, D. \& Saxena, S. Depression: a global public health concern Vol. 1. WHO Department of Mental Health and Substance Abuse 6-8 (2012).

2. López, A. D. \& Murray, C. J. The Global Burden of Disease: A Comprehensive Assesment of Mortality and Disability from Diseases, Injuries, and Risk Factors in 1990 and Projected to 2020 (Harvard School of Public of Public Health, 1996).

3. National Institutes of Health. The Numbers Count: Mental Disorders in America (NIH Publication no. 01-4584) (National Institutes of Health, Bethesda, 2014).

4. Weissman, M. M. \& Olfson, M. Depression in women: implications for health care research. Science 269, 799 (1995).

5. Desai, H. D. \& Jann, M. W. Major depression in women: a review of the literature. J. Am. Pharm. Assoc. 40, 525-537 (1999).

6. World Health Organization Department of Mental Health and Substance Dependence. Gender Disparities in Mental Health (World Health Organization, Geneva, 2013).

7. Doyal, L. Sex, gender, and health: the need for a new approach. Br. Med. J. 323, 1061 (2001).

8. Pinn, V. W. Sex and gender factors in medical studies: implications for health and clinical practice. JAMA 289, 397-400 (2003).

9. Vlassoff, C. Gender differences in determinants and consequences of health and illness. J. Health Popul. Nutr. 25, 47-61 (2007).

10. Gahagan, J., Gray, K. \& Whynacht, A. Sex and gender matter in health research: addressing health inequities in health research reporting. Int. J. Equity Health 14, 1 (2015). 
11. Sanders, A. R., Detera-Wadleigh, S. D., \& Gershon, E. S. Molecular genetics of mood disorders. In: Charney DDS, Nestler EJ, Bunney ES, eds. Neurobiology of Mental Illness. 1st ed. New York: Oxford; 1999:299-316.

12. Sullivan, P. F., Neale, M. C. \& Kendler, K. S. Genetic epidemiology of major depression: review and meta-analysis. Am. J. Psychiatry 157, 1552-1562 (2000).

13. Fava, M. \& Kendler, K. S. Major depressive disorder. Neuron 28, 335-341 (2000).

14. Canli, T., Desmond, J. E., Zhao, Z. \& Gabrieli, J. D. Sex differences in the neural basis of emotional memories. Proc. Natl Acad. Sci. USA 99, 10789-10794 (2002).

15. Ruigrok, A. N. et al. A meta-analysis of sex differences in human brain structure. Neurosci. Biobehav. Rev. 39, 34-50 (2014).

16. Eagly, A. H. \& Wood, W. The origins of sex differences in human behavior: evolved dispositions versus social roles. Am. Psychol. 54, 408 (1999).

17. Courtenay, W. H. Constructions of masculinity and their influence on men's well-being: a theory of gender and health. Soc. Sci. Med. 50, 1385-1401 (2000).

18. Evans, J., Frank, B., Oliffe, J. L. \& Gregory, D. Health, illness, men and masculinities (HIMM): a theoretical framework for understanding men and their health. J. Men's Health 8, 7-15 (2011).

19. Emslie, C., Ridge, D., Ziebland, S. \& Hunt, K. Men's accounts of depression: reconstructing or resisting hegemonic masculinity? Soc. Sci. Med. 62 2246-2257 (2006).

20. Goldstein, J. M., Jerram, M., Abbs, B., Whitfield-Gabrieli, S. \& Makris, N. Sex differences in stress response circuitry activation dependent on female hormonal cycle. J. Neurosci. 30, 431-438 (2010).

21. Chua, P. \& Fujino, D. C. Negotiating new Asian-American masculinities: attitudes and gender expectations. J. Men's Stud. 7, 391-413 (1999).

22. Pleck, J. H. The gender role strain paradigm: an update. In: Levant RF, Pollack WS. eds. A New Psychology of Men, New York: Basic Books, 11-32 (1995).

23. Maume, D. J. \& Ruppanner, L. State liberalism, female supervisors, and the gender wage gap. Soc. Sci. Res. 50, 126-138 (2015).

24. Platt, J., Prins, S., Bates, L. \& Keyes, K. Unequal depression for equal work? How the wage gap explains gendered disparities in mood disorders. Soc. Sci. Med. 149, 1-8 (2016)

25. Orloff, A. S. Gender and the social rights of citizenship: the comparative analysis of gender relations and welfare states. Am. Sociol. Rev. 58, 303-328 (1993).

26. Moss, N. E. Gender equity and socioeconomic inequality: a framework for the patterning of women's health. Soc. Sci. Med. 54, 649-661 (2002).

27. Walby, S., Allen, J., Simmons, J. Domestic Violence, Sexual Assault and Stalking: Findings from the British Crime Survey (Home Office Research, Development and Statistics Directorate, London, 2004).

28. Borrell, C. et al. Influence of macrosocial policies on women's health and gender inequalities in health. Epidemiol. Rev. 36, 31-48 (2014).

29. World Health Organization. Gender Differences in the Epidemiology of Affective Disorders and Schizophrenia (World Health Organization, Geneva, 1997).

30. World Health Organization. Women's Mental Health: An Evidence Based Review (World Health Organization, Geneva, 2000).

31. Van de Velde, S., Huijts, T., Bracke, P. \& Bambra, C. Macro-level gender equality and depression in men and women in Europe. Sociol. Health IIIn. 35, 682-698 (2013).

32. Hopcroft, R. L. \& Bradley, D. B. The sex difference in depression across 29 countries. Social. Forces 85, 1483-1507 (2007).

33. Hagen, E. H. \& Rosenström, T. Explaining the sex difference in depression with a unified bargaining model of anger and depression. Evol. Med. Public Health 2016, 117-132 (2016).

34. Seedat, S. et al. Cross-national associations between gender and mental disorders in the World Health Organization World Mental Health Surveys. Arch. Gen. Psychiatry 66, 785-795 (2009).

35. Reiss, F. Socioeconomic inequalities and mental health problems in children and adolescents: a systematic review. Soc. Sci. Med. 90, 24-31 (2013).

36. Marmot, M. \& Bell, R. Fair society, healthy lives. Public. Health 126, S4-S10 (2012).

37. Wilkinson, R. \& Pickett, K. The Spirit Level: Why Equality is Better for Everyone (Penguin UK, 2010).

38. Black, R. E. et al. Maternal and child undernutrition and overweight in lowincome and middle-income countries. Lancet 382, 427-451 (2013).

39. Eckersley, R. Beyond inequality: acknowledging the complexity of social determinants of health. Soc. Sci. Med. 147, 121-125 (2015).

40. Foverskov, E. \& Holm, A. Socioeconomic inequality in health in the British household panel: tests of the social causation, health selection and the indirect selection hypothesis using dynamic fixed effects panel models. Soc Sci. Med. 150, 172-183 (2016).
41. Undurraga, E. A., Behrman, J. R., Leonard, W. R. \& Godoy, R. A. The effects of community income inequality on health: evidence from a randomized control trial in the Bolivian Amazon. Soc. Sci. Med. 149, 66-75 (2016).

42. Bhargava, A., Jamison, D. T., Lau, L. J. \& Murray, C. J. Modeling the effects of health on economic growth. J. Health Econ. 20, 423-440 (2001).

43. Pickett, K. E. \& Wilkinson, R. G. Inequality: an underacknowledged source of mental illness and distress. Br. J. Psychiatry 197, 426-428 (2010).

44. Murali, V. \& Oyebode, F. Poverty, social inequality and mental health. Adv. Psychiatr. Treat. 10, 216-224 (2004).

45. Ramon, S. Inequality in mental health: The relevance of current research and understanding to potentially effective social work responses. Radic. Psychol. $\mathbf{6}$, 1-23 (2007).

46. World Health Organization. Mental health: responding to the call for action, report by the Secretariat Vol. 55. 55th World Health Assembly A (World Health Organization, Geneva, 2002).

47. World Health Organization. Mental health action plan 2013-2020. (2013) http://www.who.int/mental_health/publications/action_plan/en/.

48. Gitto, L., Noh, Y.-H. \& Andrés, A. R. An Instrumental Variable Probit (IVP) analysis on depressed mood in Korea: the impact of gender differences and other socio-economic factors. Int. J. Health Policy Manag. 4, 523 (2015).

49. Seguino, S. Gender inequality and economic growth: a cross-country analysis. World Dev. 28, 1211-1230 (2000).

50. Bhan, N., Rao, K. D. \& Kachwaha, S. Health inequalities research in India: a review of trends and themes in the literature since the 1990s. Int. J. Equity Health 15, 166 (2016).

51. Cheng, H. G. et al. Social correlates of mental, neurological, and substance use disorders in China and India: a review. Lancet Psychiatry 3, 882-899 (2016).

52. Schwab, K. \& Sala-i-Martin, X. The Global Competitiveness Report 2013-2014 Full data edn (World Economic Forum, 2015).

53. Seth, S. Inequality, interactions, and human development. J. Human Dev. Capab. 10, 375-396 (2009).

54. Hausmann, R., Tyson, L. \& Zahidi, S. The Global Gender Gap Report (World Economic Forum, 2009).

55. World Health Organization. The ICD-10 Classification of Mental and Behavioural Disorders: Diagnostic Criteria for Research, Vol. 2 (World Health Organization, Geneva, 1993).

56. American Psychiatric Association. Diagnostic and Statistical Manual of Mental Disorders (DSM-5 ${ }^{\circledR}$ ) (American Psychiatric Association, Arlington, VA, 2013).

57. Whiteford, H. A. et al. Global burden of disease attributable to mental and substance use disorders: findings from the Global Burden of Disease Study 2010. Lancet 382, 1575-1586 (2013).

58. Murray, C. \& Lopez, A. D. Quantifying disability: data, methods and results. Bull. World Health Organ. 72, 481 (1994).

59. Lopez, A. D. \& Murray, C. C. The global burden of disease, 1990-2020. Nat. Med. 4, 1241 (1998).

60. Mathers, C. D. et al. Global Burden of Disease 2000: Version 2 Methods and Results (World Health Organization, Geneva, 2002).

61. Mathers, C. The Global Burden of Disease: 2004 Update (World Health Organization, Geneva, 2008).

62. West, B.T., Welch, K.B. \& Galecki, A.T. (with Contributions from Brenda W. Gillespie) (2014). Linear Mixed Models: A Practical Guide using Statistical Software, Second Edition. Chapman Hall / CRC Press: Boca Raton, FL.

63. StataCorp, L. Stata data analysis and statistical Software. Spec. Ed. Release 10 733 (2007).

64. Wada, K et al. Relationship between the onset of depression and stress response measured by the Brief Job Stress Questionnaire among Japanese employees: a cohort study. PLOS ONE 8, e56319 (2013).

65. Grossman, M. \& Wood, W. Sex differences in intensity of emotional experience: a social role interpretation. J. Pers. Soc. Psychol. 65, 1010 (1993).

66. Lungu, O., Potvin, S., Tikàsz, A. \& Mendrek, A. Sex differences in effective frontolimbic connectivity during negative emotion processing. Psychoneuroendocrinology 62, 180-188 (2015).

67. Naninck, E., Lucassen, P. \& Bakker, J. Sex differences in adolescent depression: do sex hormones determine vulnerability? J. Neuroendocrinol. 23, 383-392 (2011).

68. Parker, G. \& Brotchie, H. Gender differences in depression. Int. Rev. Psychiatry 22, 429-436 (2010).

69. Muntaner, C., Eaton, W., Diala, C., Kessler, R. \& Sorlie, P. Social class, assets, organizational control and the prevalence of common groups of psychiatric disorders. Soc. Sci. Med. 47, 2043-2053 (1998). 
70. Pollack, C. E. et al. Should health studies measure wealth?: a systematic review. Am. J. Prev. Med. 33, 250-264 (2007).

71. Carter, K. N., Blakely, T., Collings, S., Gunasekara, F. I. \& Richardson, K. What is the association between wealth and mental health? J. Epidemiol. Community Health 63, 221-226 (2009).

72. Ferrari, A. J. et al. The burden attributable to mental and substance use disorders as risk factors for suicide: findings from the Global Burden of Disease Study 2010. PLoS ONE 9, e91936 (2014).

73. Lopez, A. D., Mathers, C. D., Ezzati, M., Jamison, D. T. \& Murray, C. J. Global and regional burden of disease and risk factors, 2001: systematic analysis of population health data. Lancet 367, 1747-1757 (2006).

74. McGee, A., McGee, P. \& Pan, J. Performance pay, competitiveness, and the gender wage gap: evidence from the United States. Econ. Lett. 128, 35-38 (2015).

75. Guimarães, CRFF. \& Silva, JR. Pay gap by gender in the tourism industry of Brazil. Tour. Manag. 52, 440-450 (2016).

76. Mandel, $\mathrm{H}$. The role of occupational attributes in gender earnings inequality, 1970-2010. Soc. Sci. Res. 55, 122-138 (2016).

77. Jagger, $C$. et al. Inequalities in healthy life years in the 25 countries of the European Union in 2005: a cross-national meta-regression analysis. Lancet $\mathbf{3 7 2}$ 2124-2131 (2009)
78. Oksuzyan, A., Shkolnikova, M., Vaupel, J., Christensen, K. \& Shkolnikov, V. Sex differences in health and mortality in Moscow and Denmark. Eur. J. Epidemiol. 29, 243-252 (2014).

79. World Health Organization. Ageing and Life Course, Family and Community Health: WHO Global Report on Falls Prevention in Older Age (World Health Organization, Geneva, 2008)

80. Nusselder, W., Looman, C., Oyen, H., Robine, J.-M. \& Jagger, C. Gender differences in health of EU10 and EU15 populations: the double burden of EU10 men. Eur. J. Ageing 7, 219-227 (2010).

81. Whiteford, H., Ferrari, A. \& Degenhardt, L. Global burden of disease studies: implications for mental and substance use disorders. Health Aff. 35, 1114-1120 (2016).

82. Muehlenhard, C. L. \& Peterson, Z. D. Distinguishing between sex and gender: history, current conceptualizations, and implications. Sex. Roles 64, 791-803 (2011).

83. World Health Organization. Gender Mainstreaming for Health Managers: A Practical Approach World Health Organization, Geneva, 2011). 